\title{
Alternative splicing of SV40 early pre-mRNA is determined by branch site selection
}

\author{
Jonathan C.S. Noble, Carol Prives, and James L. Manley \\ Department of Biological Sciences, Columbia University, New York, New York 10027 USA
}

\begin{abstract}
Splicing of SV40 early pre-mRNA to alternative large-T and small-t mRNAs involves the utilization of multiple lariat branch sites. To determine the functional significance of these sites, we constructed and analyzed a set of base substitution mutants in which the major branch acceptors were altered, either singly or in combination. The ratio of large- $T$ to small-t mRNAs produced in vivo was found to vary by over 100 -fold between different mutants. When splicing was assayed in vitro with a standard pre-RNA, which results in splicing almost exclusively to large-T mRNA, the patterns of branch site utilization were altered dramatically, although the mutations were essentially without effect on splicing efficiency. However, use of a $5^{\prime}$ truncated pre-RNA, which results in a splicing pattern that reflects the in vivo alternative splicing potential of this pre-RNA, revealed a strong correlation between the effects of the base substitutions on branch site selection and alternative splicesite utilization. An RNase protection analysis of factor interactions with the $5^{\prime}$ splice sites and branch sites in wild-type and mutant pre-RNAs suggests that a competition for different branch sites plays a crucial role in the assembly of 'alternative' spliceosomes, thereby controlling alternative splice-site selection.
\end{abstract}

[Key Words: Pre-mRNA processing; alternative splicing; lariat branch site]

Received July 26, 1988; revised version accepted September 26, 1988.

Pre-mRNA splicing has been shown to involve a twostep reaction (Domdey et al. 1984; Grabowski et al. 1984; Padgett et al. 1984; Rodriguez et al. 1984; Ruskin et al. 1984; Lin et al. 1985; for reviews, see Green 1986; Padgett et al. 1986). In the first step, the pre-mRNA is cleaved at the $5^{\prime}$ splice junction and the $5^{\prime}$ end of the intron is joined by a $2^{\prime}-5^{\prime}$ phosphodiester linkage, or branch, to a nucleotide upstream of the $3^{\prime}$ splice junction. This step, which appears to consist of two concerted subreactions, generates 'free' 5 ' exon and lariat intron $-3^{\prime}$ exon intermediates. In the second step, the lariat intron $-3^{\prime}$ exon is cleaved at the $3^{\prime}$ splice junction and the $5^{\prime}$ and $3^{\prime}$ exons are ligated, again in a concerted manner, generating a free lariat intron and spliced product.

In all yeast and the majority of higher eukaryotic introns examined thus far, only a single authentic branch site has been found to be used in any one intron. In yeast, this stringency is believed to be determined by a highly conserved sequence found at the branch site, UACUAAC (Domdey et al. 1984; Rodriguez et al. 1984), of which the penultimate nucleotide is the site of the $2^{\prime}-5^{\prime}$ phosphodiester linkage (Lin et al. 1985). Deletion of this sequence (Langford and Gallwitz 1983; Pikielny et al. 1983 ) or point mutations within it have been shown to inhibit splicing dramatically (Langford et al. 1984; Jacquier et al. 1985; Newman et al. 1985; Fouser and
Friesen 1986; Vijayraghavan et al. 1986). In higher eukaryotes, sequences surrounding the branch site conform to a more liberally defined consensus, YNCURAY (Zeitlin and Efstratiadis 1984; Reed and Maniatis 1985), which shares homology with the yeast element (Keller and Noon 1984/. Within this sequence, only the branch nucleotide has been found to be invariant. Point mutations involving the branch nucleotide have been shown to have varied effects on the efficiency of splicing in vitro (Hornig et al. 1986; Freyer et al. 1987). The majority of branch sites in higher eukaryotes thus far mapped have been found to lie within 18-37 nucleotides upstream of the $3^{\prime}$ splice junction (Reed and Maniatis 1985; for an exception, see Gattoni et al. 1988). For deletion mutants that remove the authentic branch site, cryptic branch sites, invariably As, which lie within this prescribed distance but are surrounded by sequences that lack homology to the consensus, are used instead (Padgett et al. 1985; Ruskin et al. 1985).

A number of factors have been shown to interact with the pre-mRNA during splicing. U1 snRNP binds to $5^{\prime}$ splice sites (Mount et al. 1983; Black et al. 1985) in an interaction that involves, at least in part, base-pairing between the $5^{\prime}$ end of U1 snRNA and the $5^{\prime}$ splice site (Zhuang and Weiner 1986). Several factors have been found to interact with the branch site region and adjacent $3^{\prime}$ splice site. These include U2 snRNP (Black et al. 
1985; Krainer and Maniatis 1985), which interacts with the branch point region (Black et al. 1985; Chabot and Steitz 1987), and another snRNP, probably U5, which interacts with the $3^{\prime}$ splice site (Chabot et al. 1985). In yeast, a base-pairing interaction between an internal region of snR20 (the yeast analog of U2 snRNA) and the UACUAAC branch site consensus (Parker et al. 1987) has been demonstrated. The adenosine that serves as the branch acceptor is bulged from the proposed RNA : RNA duplex generated by this interaction, and a factor distinct from snR20 appears to be required for recognition of this bulged acceptor nucleotide /Cuoto et al. 1987). In higher eukaryotes, a factor that binds to the $3^{\prime}$ splice site and facilitates association of U2 snRNP with the branch site region (Ruskin et al. 1988), and another factor, thought to be associated with U5 snRNP also interacts with the $3^{\prime}$ splice site (Gerke and Steitz 1986; Tazi et al. 1986), have been described. Aside from their interactions with pre-mRNA, these snRNPs are thought to interact with each other during assembly of the spliceosome, the multicomponent complex within which splicing has been shown to occur (Brody and Abelson 1985; Frendewey and Keller 1985; Grabowski et al. 1985; Bindereif and Green 1986; Grabowski and Sharp 1986; Konarska and Sharp 1987).

The majority of studies on the mechanism of premRNA splicing have been performed using 'simple' substrates, i.e., pre-RNAs that are not spliced by alternative pathways (for review of alternative splicing, see Breitbart et al. 1987). Little is known about the sequences and factors that control alternative splice-site selection. To address this problem, we have employed SV40 early premRNA as a model substrate. SV40 early pre-RNA is spliced to large-T and small-t mRNAs by the use of two alternative $5^{\prime}$ splice sites joined to a single shared $3^{\prime}$ splice site. A number of factors influence the usage of alternative $5^{\prime}$ splice sites, including the size of the small-t intron (Fu and Manley 1987; Fu et al. 1988a), the sequences of the $5^{\prime}$ splice sites (Zhuang et al. 1987), the purine/pyrimidine content of sequences immediately upstream of the $3^{\prime}$ splice junction (Fu et al. 1988b), and, possibly, cell-specific trans-acting factors (Fu and Manley 1987; Noble et al. 1987). Our previous analysis of the products generated by splicing of this precursor revealed that the large- $\mathrm{T}$ splice uses at least six alternative branch sites, whereas small-t splicing uses only one, the most downstream of those employed by large $T$ (Noble et al. 1987). The fact that multiple branch sites have been detected only in an alternatively spliced preRNA, coupled with our observation that the branch sites used most frequently vary between different cell types in a manner correlated with differences in $5^{\prime}$ splice site usage (Noble et al. 1987), raises the possibility that selection of branch sites may be a controlling step in the alternative splicing pathway of SV40 early pre-mRNA. To test this hypothesis, we have analyzed the effects of mutating the major branch acceptors on splicing, branch formation, and the interaction of factors with the premRNA. The results suggest that branch site utilization does indeed play a crucial role in alternative splicing of this pre-mRNA.

\section{Results}

\section{Large- $T$ splicing in vitro uses all four nucleotides as branch acceptors}

Our previous analysis of SV40 early pre-mRNA splicing products in vitro, which involved direct fingerprint analysis of the large- $T$ and small-t introns, indicated that splicing to large- $T$ mRNA utilized at least six alternative branch sites, all As, between 18 and 32 nucleotides upstream of the $3^{\prime}$ splice junction, whereas small-t splicing used a single $A$, the most downstream of those employed by large $\mathrm{T}$ (Noble et al. 1987). Because minor branched nucleotides, particularly non-A residues, may have gone undetected by the fingerprint analysis employed, we reexamined the patterns of branch sites used by large- $\mathrm{T}$ and small-t splicing by primer extension. Primer extension of branched RNA has been shown to stop at the residue preceding the branch nucleotide (see Rodriguez et al. 1984). The results of such an analysis of lariat introns is shown in Figure $1 \mathrm{~A}$, and the branch points reproducibly detected are summarized schematically in Figure 1B. In addition to those sites mapped previously, large- $\mathrm{T}$ splicing uses three other nucleotides as branch acceptors: a G (25), a C (27), and a U (29). None of these primer extension stops was observed when debranched introns (Ruskin and Green 1985a) were analyzed (results for small-t intron not shown). Thus, large$T$ splicing is unusual not only because it can use as many as nine distinct branch sites but also because it appears to use all four nucleotides as branch acceptors. The results of a similar analysis of the branch sites used in small-t splicing (Fig. 1A), which was detected in vitro only when pre-RNAs from which the large- $T$ splice site was deleted (see Noble et al. 1987), indicate that in addition to the site observed previously (position 18), a lesser degree of branching occurs to the preceeding A (19). Positions 18 and 19 are thus used as branch sites in both large-T and small-t splicing. Although the primer extension method has been shown in some instances to be subject to template-independent nucleotide addition, generating products 1 nucleotide longer than expected (Fouser and Freisen 1986; Shelness et al. 1987), we believe, from the results of the mutational study described below, that all of these additional blocks to extension, with the possible exception of the $G$ at position 25 , correspond to branches.

\section{Large- $T$ and small-t splicing exhibit different branch site requirements in vivo}

To study the function of the multiple branch sites used in large-T splicing, we replaced, singly or in combination, all five of the major branch nucleotides used in splicing of the early precursor, corresponding to positions $18,19,24,27$, and 32 (see Fig. 1 C). In each case, the nucleotides at these positions were replaced with $U$, a selection based on the observed inefficiency with which $\mathrm{U}$ (as opposed to $\mathrm{A}$ or $\mathrm{C}$, the replaced nucleotides), is used as a branch acceptor (Hornig et al. 1986). To assess the effects of each mutation, or set of mutations, on the 
Noble et al.

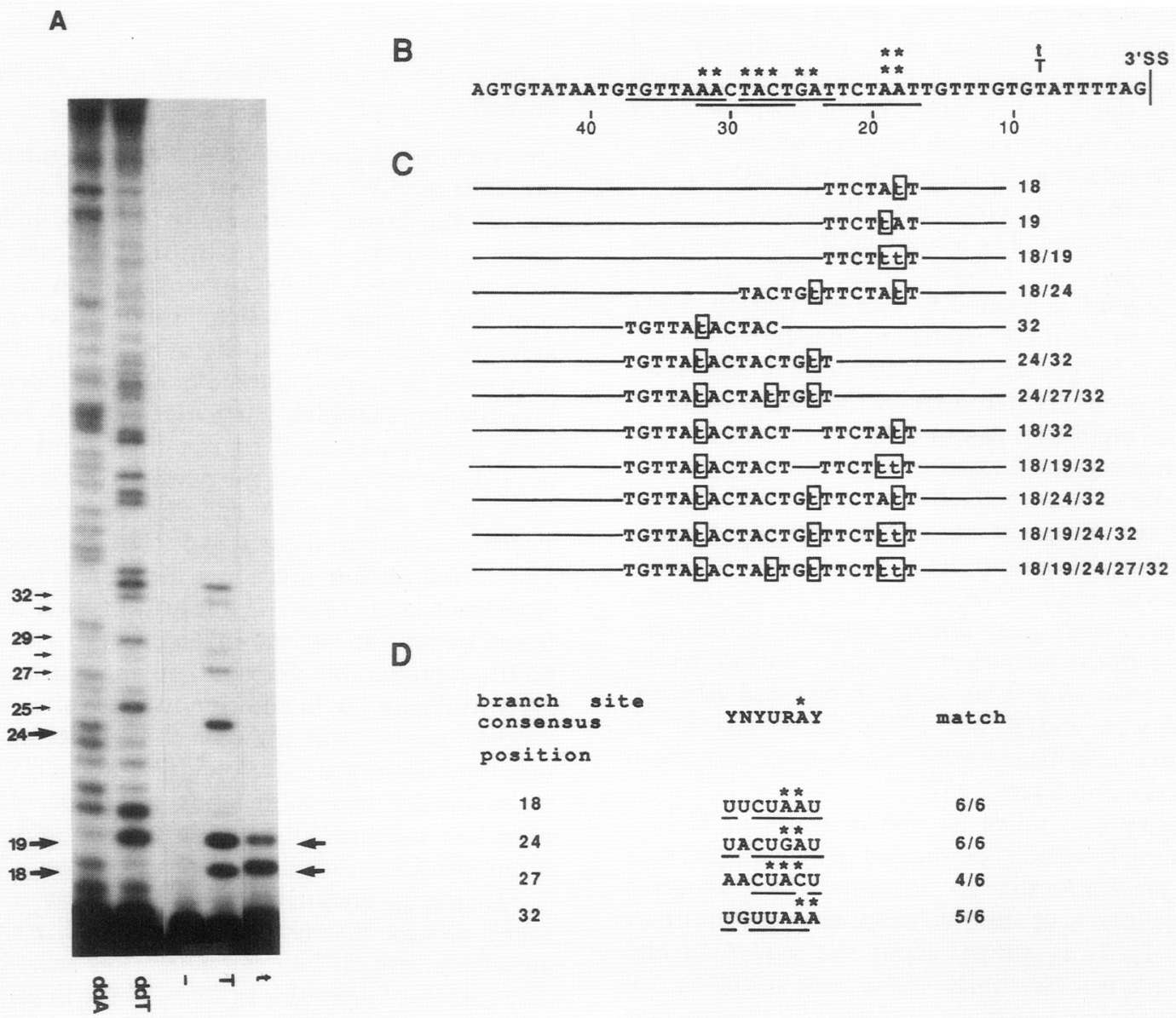

Figure 1. Branch sites used in splicing of SV40 early pre-RNA. (A) Primer extension mapping of branch sites used in large-T and small-t splicing. Large- $T$ lariat $(T)$ or debranched $(-)$ and small-t lariat $(t)$ introns were purified from in vitro splicing reactions performed using full-length or 5' truncated precursors, respectively, and analyzed by primer extension using a primer complementary to the $3^{\prime}$ end of the $\mathrm{T} / \mathrm{t}$ intron (see Materials and methods). Primer extension products corresponding to the indicated branched nucleotides are indicated by arrows, the size of the arrow corresponding approximately to the efficiency with which a given branch site is used. Markers are from dideoxy sequencing reactions performed using the same primer with precursor RNA as the template. $(B)$ Schematic summary of the branch sites used by large-T and small-t splicing. $\left({ }^{*}\right)$ The positions of the branch sites. Sequences with homology to the mammalian branch site consensus sequence are underlined. $(C)$ Nucleotide sequences of branchsite point mutants. Each mutant is named according to the positions substituted. Substitutions are represented by the lowercase $t$ and are boxed. For each mutation, the sequence surrounding the substitution that shares homology with the mammalian branch site consensus is presented. For mutants containing a substitution at position 32, the consensus sequence centered on position 27 is also shown, as the match of this branch site to the consensus is improved by this mutation. (D) Homology of $\mathrm{T} / \mathrm{t}$ branch sites to the consensus. Each of the four $\mathrm{T} / \mathrm{t}$ branch site sequences are aligned for best fit with the mammalian consensus. The position of the 'branch acceptor' nucleotide in each is indicated on the left, the match to the consensus is given on the right, and positions showing homology with the consensus are underlined. $\left({ }^{*}\right)$ Nucleotides used as branch acceptors in large-T splicing.

relative efficiency of large- $T$ and small-t splicing, each mutant was reconstructed into the plasmid pSTER for analysis in vivo. The resulting mutant plasmids, which contain the entire SV40 early region (Fu and Manley 1987), were then used to transfect HeLa cells, and the efficiencies of splicing to large-T and small-t mRNAs were analyzed by nuclease S1 mapping of cytoplasmic RNA isolated after transient expression.

The results of this analysis (shown in Fig. 2) can be summarized in essentially three points, presented in quantitative terms in Table 1. First, all mutants containing $\mathrm{A} \rightarrow \mathrm{U}$ substitutions of the most downstream branch acceptors, at positions 18 and 19 , reduced the efficiency of small-t splicing relative to large $T$. This effect was particularly dramatic for mutants altered at position 18 , the major branch acceptor for small-t splicing in the wild type, but was also observed for the mutant containing a single substitution at position 19 . The double mutant in which both As at positions 18 and 19 were replaced by Us produced no detectable small-t mRNA. Second, all mutants containing substitutions of only the more upstream branch acceptors, at positions 24, 27, and/or 32, reduced the efficiency of large- $T$ splicing relative to small $t$. This effect was apparent to a small but 
A

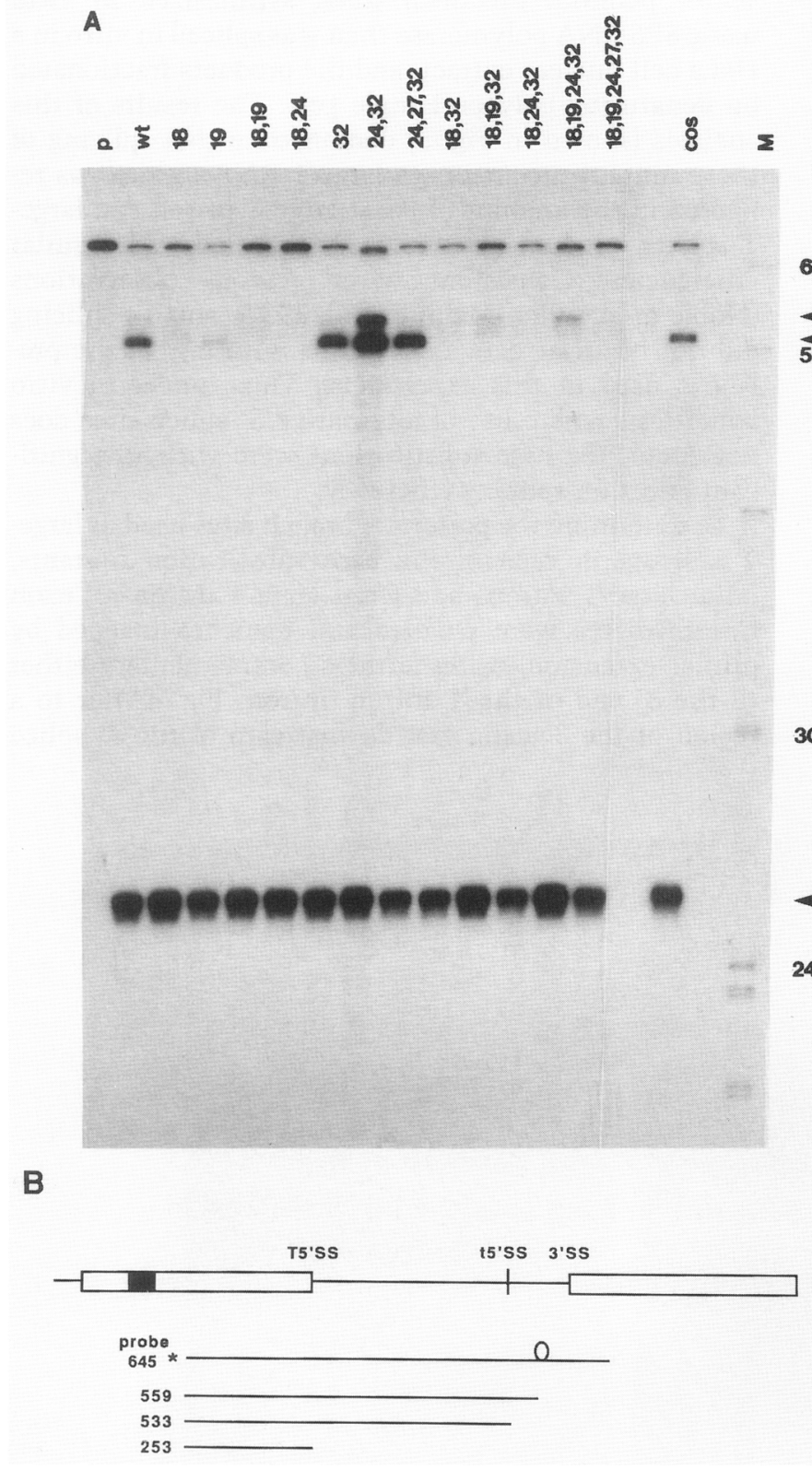

622 $\sum_{527}^{-p}$
Figure 2. Nuclease $\mathrm{S} 1$ analysis of the effects of branch acceptor mutations on splicing of SV40 early pre-mRNA in vivo. (A) Cytoplasmic RNA was extracted from HeLa cells tranfected with the wild type and each of the branch site mutants and analyzed as described in Materials and methods. Spliced large- $T(T)$ and small-t $(t)$ mRNAs are represented by the protected fragments indicated. $(\mathrm{P}) \mathrm{A}$ fragment corresponding to precursor RNA /whose sequences diverges from the probe at a position $\sim 30$ nucleotides downstream of the small-t $5^{\prime}$ splice site). cos displays an analysis of cytoplasmic RNA extracted from cos monkey cells. Markers are an end-labeled HpaII digest of pBR322. The probe and expected sizes of protected fragments are illustrated in $B$. significant degree in the case of the mutant containing a single substitution at position 32 , but was more pronounced for double and triple mutants in which the $\mathrm{A}$ at position 24 was also replaced. (The increased amount of precursor detected with mutant 24, 32 resulted from nuclear leakage during RNA isolation and was not detected in other experiments.) The effects of these two sets of mutations was quantitatively distinct. In the case of branch acceptors 18 and 19, the effect on small-t splicing was on the order of a 20 - to 30 -fold reduction relative to large $T$, whereas mutations of branch acceptors 24,27 , and 32 reduced large-T splicing only 3 - to 4 -fold relative to small $\mathrm{t}$ (see Table 1). Third, mutant pre-mRNAs containing substitutions $(A \rightarrow U, C \rightarrow U)$ at all of the major branch sites used in large- $\mathrm{T}$ splicing were still spliced to large-T mRNA. Analysis of nuclear RNA revealed the same ratios as cytoplasmic RNA and also that none of the mutants accumulated significantly higher amounts of unspliced precursor than the wild type did, indicating that all of them were spliced efficiently (data not shown).

Branch site mutations do not inhibit large-T splicing in vitro but influence the large-T branch site pattern

An important assumption involved in interpreting the effects of branch site substitutions in vivo is that the replacement of A with $U$ for a particular branch nucleotide prevents its use as an acceptor. To confirm that this is indeed the case, the pattern of branch sites used in large-T splicing in vitro was analyzed. For this analysis, each mutant was first cloned into the transcription 
Table 1. Effects of branch site substitutions on the alternative splicing pattern of SV40 early pre-mRNA in transfected HeLa cells

\begin{tabular}{lc}
\hline Plasmid & t/T mRNA ratio \\
\hline pSTER & $1: 4$ \\
18 & $1: 75$ \\
19 & $1: 20$ \\
18,19 & $<1: 125$ \\
32 & $1: 3$ \\
24,32 & $1: 1$ \\
$24,27,32$ & $1: 1$ \\
$18,19,24,32$ & $<1: 125$ \\
$18,19,24,27,32$ & $<1: 125$ \\
\hline
\end{tabular}

$t / T$ mRNA ratios were obtained by densitometry scanning of an autoradiogram similar to that shown in Fig. 1A. vector pGEM3. Precursor RNA synthesized in vitro using SP6 RNA polymerase then was spliced in vitro in a HeLa cell nuclear extract, and the products fractionated on denaturing polyacrylamide gels. The results of this analysis (shown in Fig. 3) demonstrate that splicing of these mutant precursors to large-T RNA in vitro, as reflected in the amount of lariat large- $T$ intron and largeT-spliced product accumulated, occurred with similar efficiencies. Consistent with previous observations (Noble et al. 1986, Manley et al. 1987), small-t splicing did not occur at detectable levels with any of the preRNAs used in this experiment. Thus, under in vitro conditions where use of alternative $5^{\prime}$ splice sites does not occur, the base substitutions were without significant effect on splicing efficiency.

To determine the pattern of branch sites used in large$\mathrm{T}$ splicing in each of the base substitution mutants, lariat large- $T$ introns and lariat large- $T$ intron $-3^{\prime}$ exon intermediates were purified and branches mapped by primer extension, using primers complementary either to the $3^{\prime}$ end of the $\mathrm{T}$ intron (intron; Fig. 4A) or to a region of the $3^{\prime}$ exon just downstream of the $3^{\prime}$ splice

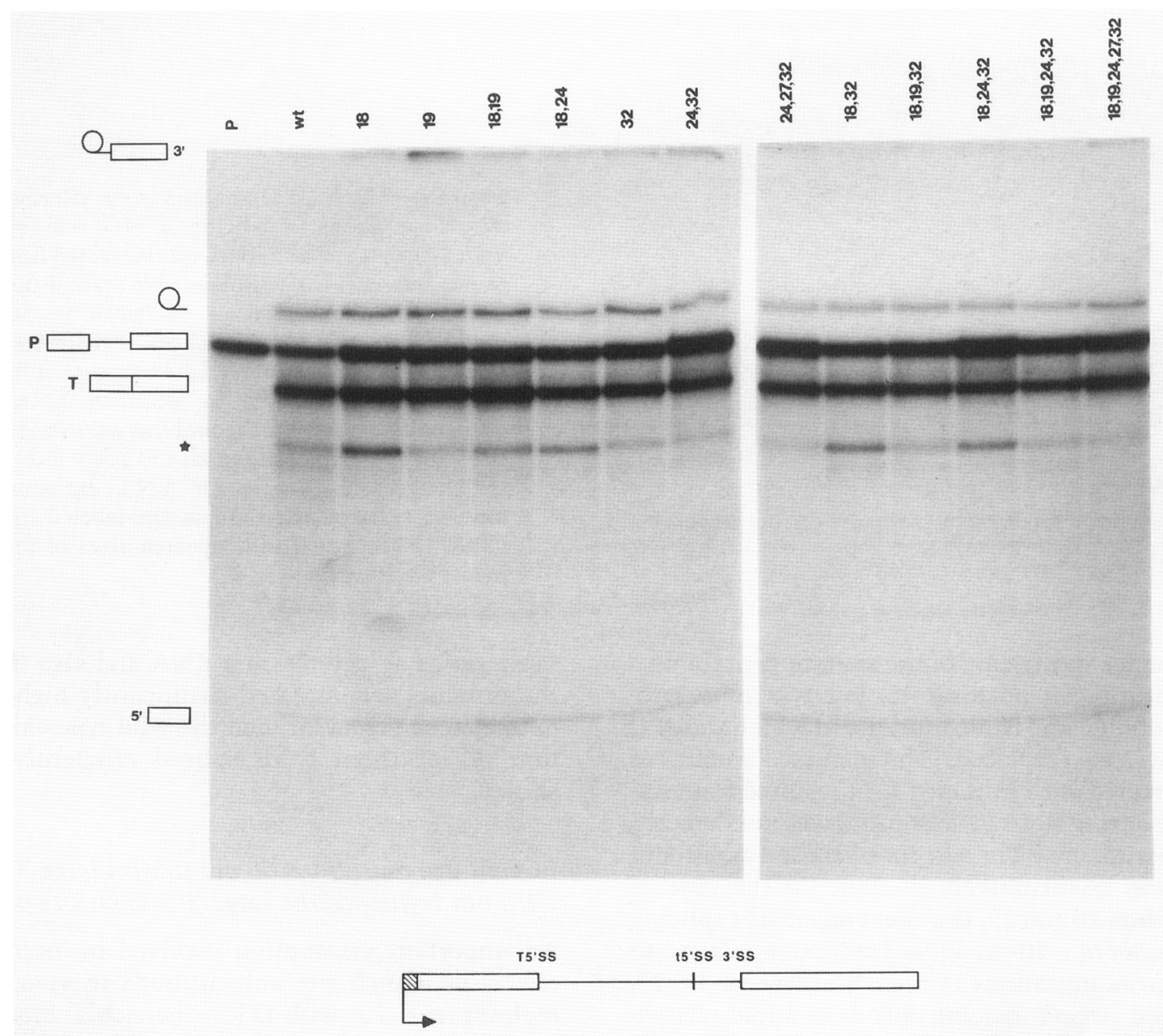

Figure 3. Effects of branch site mutations on splicing of large-T RNA in vitro. Wild-type and mutant pre-RNAs were processed in vitro, and products analyzed on $5 \%$ denaturing polyacrylamide gels. Each intermediate and product of the large-T splice is indicated on the left. (P) Precursor; (T) large-T spliced RNA. In addition, protection products corresponding to factor binding to the branch site region are indicated by a star. 
A

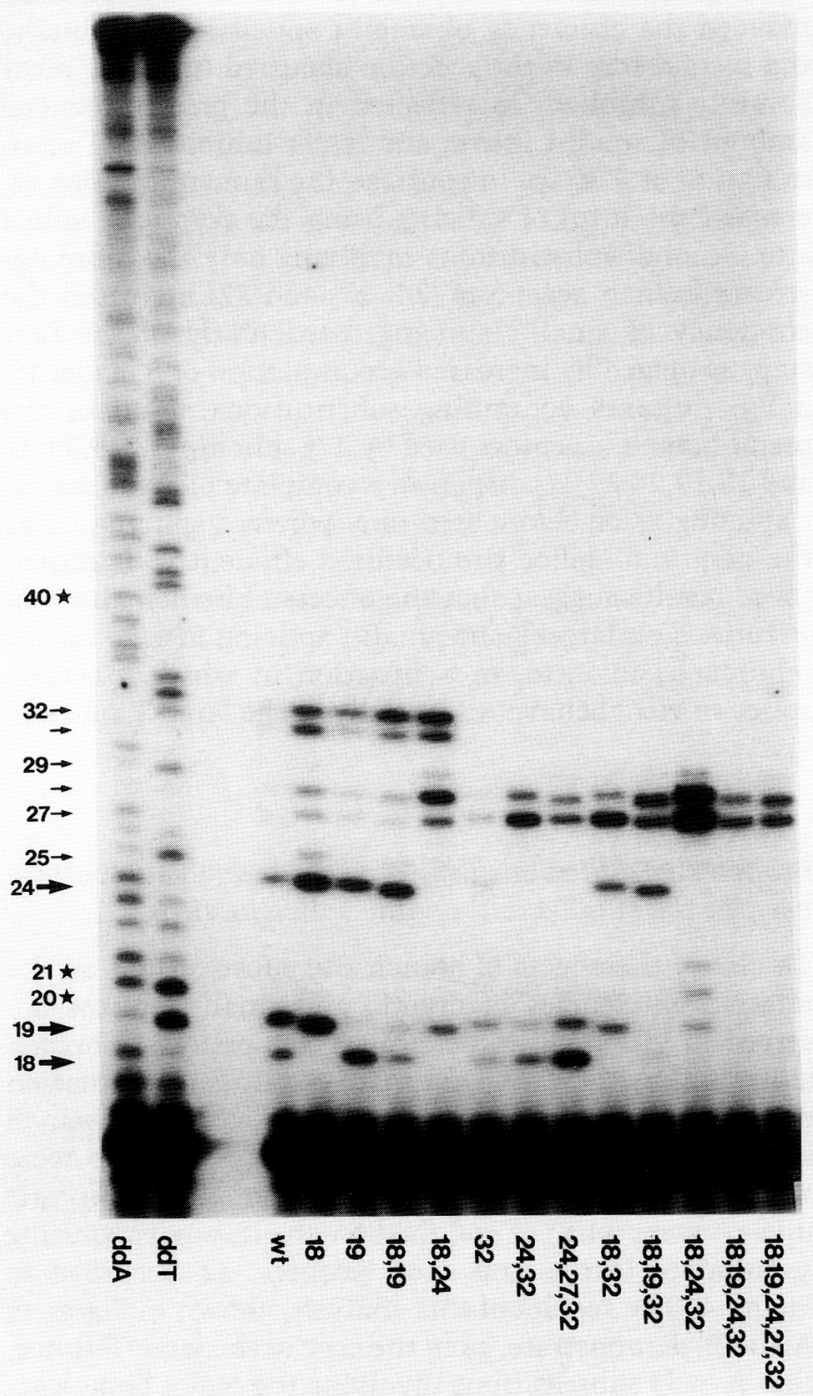

Figure 4. Branch site mutations influence the pattern of branch sites used in large-T splicing. Lariat large- $T$ introns and lariat intron-3' exon intermediates from the wild type and each of the mutants were purified as described in Fig. 1A. $|A|$ Branch sites were mapped for the intron products by primer extension using a primer complementary to the $3^{\prime}$ end of the large- $T$ intron (see Fig. 1A). Primer extension stops corresponding to the indicated branch sites used in the wild type are denoted by arrows. Three branch sites used in mutant $18,24,32$ but not in wild type are denoted by stars. $(B)$ Branch sites for the lariat intron-3' exon intermediates were mapped using a primer complementary to a region of the $3^{\prime}$ exon $\sim 55$ nucleotides downstream of the $\mathrm{T} / \mathrm{t} 3^{\prime}$ splice junction (see Materials and methods). Arrows indicate the branch sites used in the wild type. The size of the arrow in each case indicates the relative efficiency of use. A branch site used in mutant 18,24 , but not in wild type, is indicated by a star. (debr) Primer extension of the wild-type intron after pretreatment with debranching activity. Slight variations in the amounts of RNA added to reactions and/or recovery of samples prevent precise quantitative comparisons between lanes. Markers are dideoxy sequencing reactions performed using the same primer, with precursor RNA as the template.
B

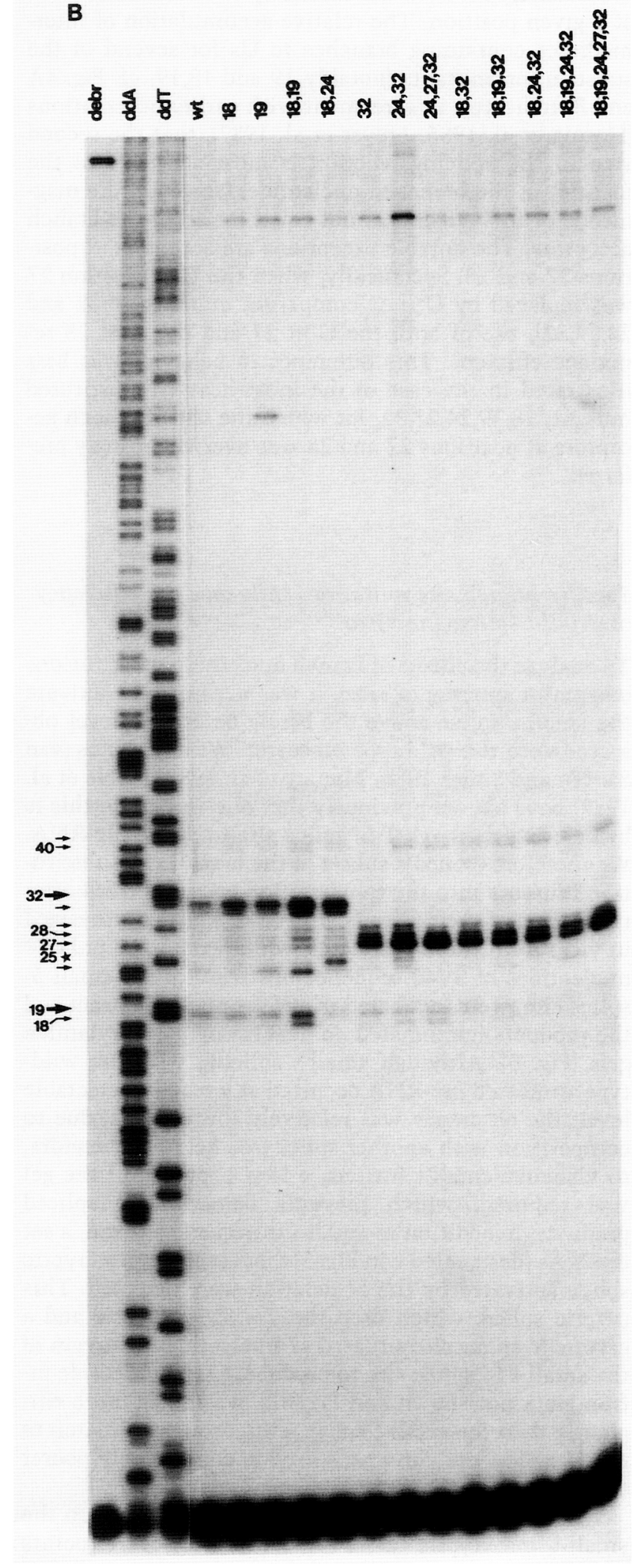


junction (intermediate; Fig. 4B). Comparing the mutant and wild-type branch site patterns for both the large- $T$ intron and intermediate; it is evident that substitution of a $\mathrm{U}$ for an $\mathrm{A}$ at a branch position in most instances dramatically reduced the efficiency of branch formation at a given position. The relative accumulation of intermediates containing branches to Us for several of the substitution mutants (notably 19 and 18,19; cf. Fig. 4A and $B$ ) indicates, in agreement with earlier observations (Hornig et al. 1986; Freyer et al. 1987), that the second step in the splicing reaction is most sensitive to the identity of the branched nucleotide. However, the magnitude of this effect was not equal for all of the branch acceptors. The notable exceptions are acceptors at positions 27 and 28. Specifically, when the $\mathrm{C}$ at position 27 was replaced by $U$ (i.e., comparing mutants 24,32 and $24,27,32$ ), use of both the $U$ at 27 and the $A$ at 28 remained efficient. This difference in behavior was best illustrated in the case of the most heavily substituted mutant, 18,19,24,27,32, for which the use of branch acceptors at positions 27 and 28 was overwhelmingly preferred.

\section{Specific branch site mutations influence the efficiency of small-t splicing in vitro}

To analyze the effects of branch nucleotide substitutions on small-t splicing in vitro, it was necessary to activate the small-t splice above the barely detectable level observed with the wild-type precursor. We and others (van Santen and Spritz 1986; Manley et al. 1987; Noble et al. 1987) have shown previously that one way to do this is by deleting the large-T 5 ' splice site from the pre-RNA. We therefore cloned a subset of the branch site substitution mutants into the transcription vector pGEM4 after truncation of their $5^{\prime}$ ends. Precursor RNAs synthesized in vitro from these templates, which contained only 70 nucleotides of SV40 sequence upstream of the small $5^{\prime}$ splice site, were incubated in a HeLa nuclear extract and the products fractionated on denaturing polyacrylamide gels (Fig. 5). Although small-t splicing with the wildtype truncated pre-RNA occurred at a readily detectable level, the efficiency was relatively low, in part, due to competition with another splice (see below). Therefore, to visualize small-t introns, a long exposure of the gel was required, which prevents detection of spliced products. In addition to small-t intron and $5^{\prime}$ exon, a set of RNAs (designated $c$ in Fig. 5) that result from a cryptic splice activated by the $5^{\prime}$ deletion were detected. This cryptic splice, which used the $\mathrm{T} / \mathrm{t} 3^{\prime}$ splice site and a cryptic $5^{\prime}$ splice site situated 47 nucleotides upstream of the small-t $5^{\prime}$ splice site to produce a 113-nucleotide intron (data not shown and Fig. 6B), was made more efficiently than the small-t splice, even though its match to the $5^{\prime}$ splice site consensus $(5 / 9)$ is considerably poorer than that of small $t(8 / 9)$.

When the effects of each branch site mutation on the small-t and cryptic splice are compared, several points are apparent. First, substitutions involving only the downstream branch acceptors (18 and 19) significantly reduced the efficiency of small-t splicing. Surprisingly, the second step in the reaction appeared to be the most severely inhibited, as reflected in the greatly reduced amount of small-t intron and lesser inhibition of accumulation of $5^{\prime}$ exon. In contrast, the same mutations increased the level of splicing using the cryptic $5^{\prime}$ splice site. Second, substitutions involving only the more upstream branch acceptors $(24,27$, and 32$)$ increased the efficiency of small-t splicing, particularly of the first step, as judged by increased accumulation of $5^{\prime}$ exon. Finally, mutants containing substitutions at all of the major branch acceptors used by $\mathrm{T} / \mathrm{t}$ splicing $(18,19,24,32$ and $18,19,24,27,32$ ) displayed a complete block of small$\mathrm{t}$ splicing at or before step one, whereas splicing using the cryptic $5^{\prime}$ splice site occurred efficiently. Together, these results suggest that the effects of branch site substitutions on large- $T$ and small-t splicing in vivo can be reproduced in vitro, in a situation in which a cryptic splice in vitro behaves essentially as the large- $T$ splice in vivo.

Branch site mutations influence the branch site pattern used in the small-t and cryptic splice in vitro

To clarify the effects of branch site substitutions on the relative efficiencies of cryptic and small-t splices observed in vitro, and to determine the pattern of branch sites used by these two alternative splices in a situation of competition paralleling existing in vivo, the branch sites used by cryptic and small-t splices in vitro were analyzed. For this purpose, the lariat small-t and cryptic introns were purified and the branch sites mapped using appropriate intron and exon primers, as described in Figure 4. The results of this analysis, shown in Figure 6, $A$ and $B$, demonstrate, as in the case of the large-T splice, that $\mathrm{A} \rightarrow \mathrm{U}$ substitutions involving the major branch acceptors effectively prevented their use as branch sites. They also suggest, when compared to the patterns of branch sites used by large-T splicing (see Fig. 4A), that the large- $T$ pattern corresponds to the effective sum of the small-t and cryptic patterns. This superimposition of branch site patterns is most evident in the case of the wild-type downstream branch acceptors. Small-t splicing displayed a clear preference for use of position 18 as an acceptor, whereas the cryptic splice preferred position 19. By comparison, large-T splicing used both 18 and 19, with only a slight preference for the latter. A similar relationship exists between branch site patterns of mutants containing substitutions involving only the more upstream branch acceptors (most notably 24,27 and $24,27,32$ ). Elimination of the upstream branch sites was compensated for by increased use of downstream sites for large-T splicing (Fig. 4A), whereas in the $5^{\prime}$ truncated pre-RNAs, use of these downstream acceptors was dominated by the small-t splice, with the cryptic splice using the more downstream acceptors to only a very limited degree. 


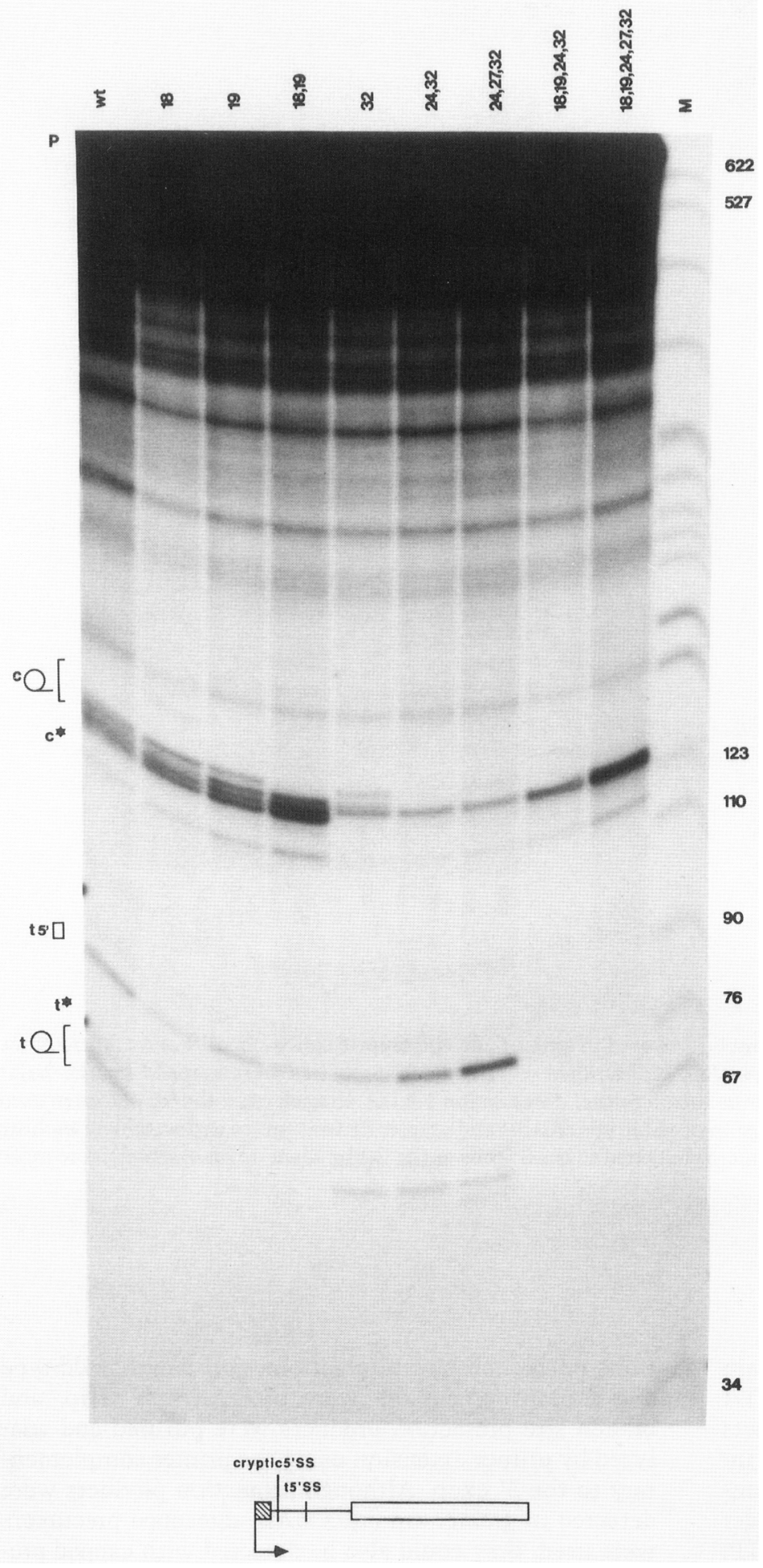

Figure 5. Effects of branch site mutations on small-t splicing in vitro. Pre-RNAs deleted for the large-T 5' splice site and containing wild-type or mutant branch site regions were processed in vitro, and the products fractionated on a $5 \%$ denaturing polyacrylamide gel. Intermediates and products of the small-t splice are indicated on the left. Among these are linear $\left(t^{*}\right)$ and lariat $(t)$ small-t introns, and the small- $t 5^{\prime}$ exon. A set of introns resulting from a splice using a cryptic $5^{\prime}$ splice site and the $T / \mathrm{t} 3^{\prime}$ splice site, including linear $\left\langle c^{\star}\right|$ and lariat $|c|$ introns, are also indicated on the left. For both the small-t and the cryptic splice, multiple lariat intron bands are evident, which correspond to the use of a different branch site in each case. Neither small-t nor cryptic spliced RNAs are apparent in this autoradiogram, due to overexposure required to detect the introns. (P) Precursor. Markers are an end-labeled HpaII digest of pBR322. Sizes indicated are in nucleotides.

Factor interactions with $T / t$ branch site region are influenced by branch acceptor mutants

lized an RNase protection assay that maps the 5' boundary of factor-RNA interactions. Specifically, previously we identified a collection of RNAs generated by protection of the early precursor at specific sites from $5^{\prime} \rightarrow 3^{\prime}$ exonuclease activity endogenous to the nuclear extract (Noble et al. 1986; see also Ruskin and Green 1985b). The $5^{\prime}$ ends of these 'protection' products were 
A

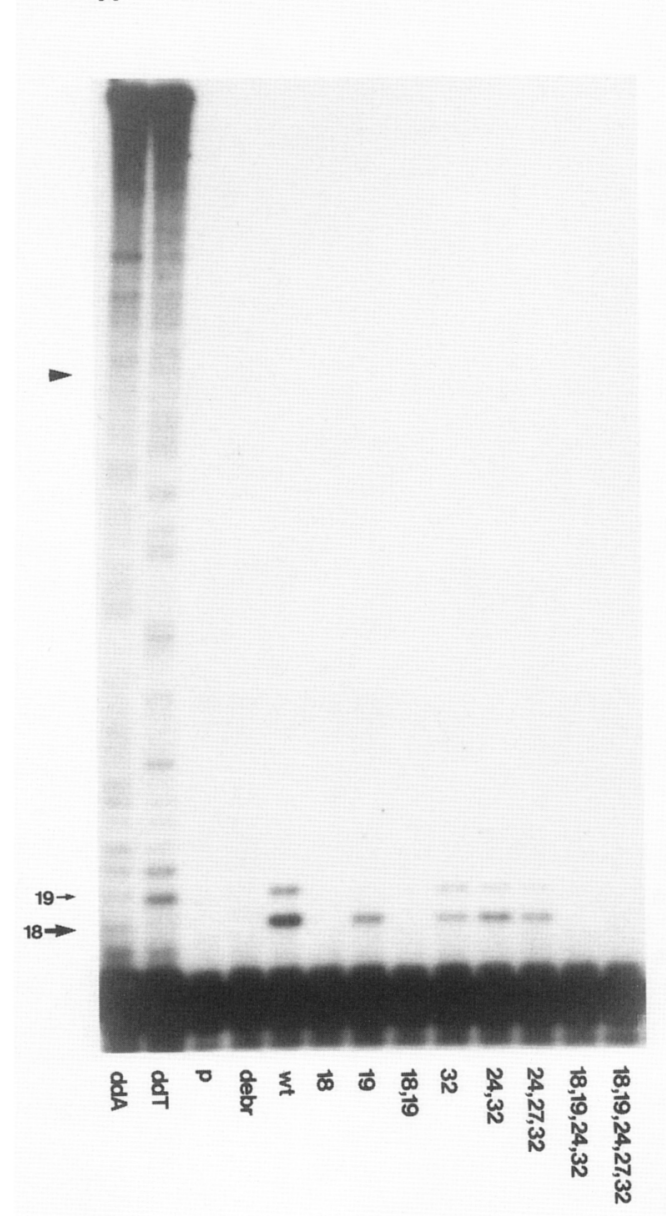

B

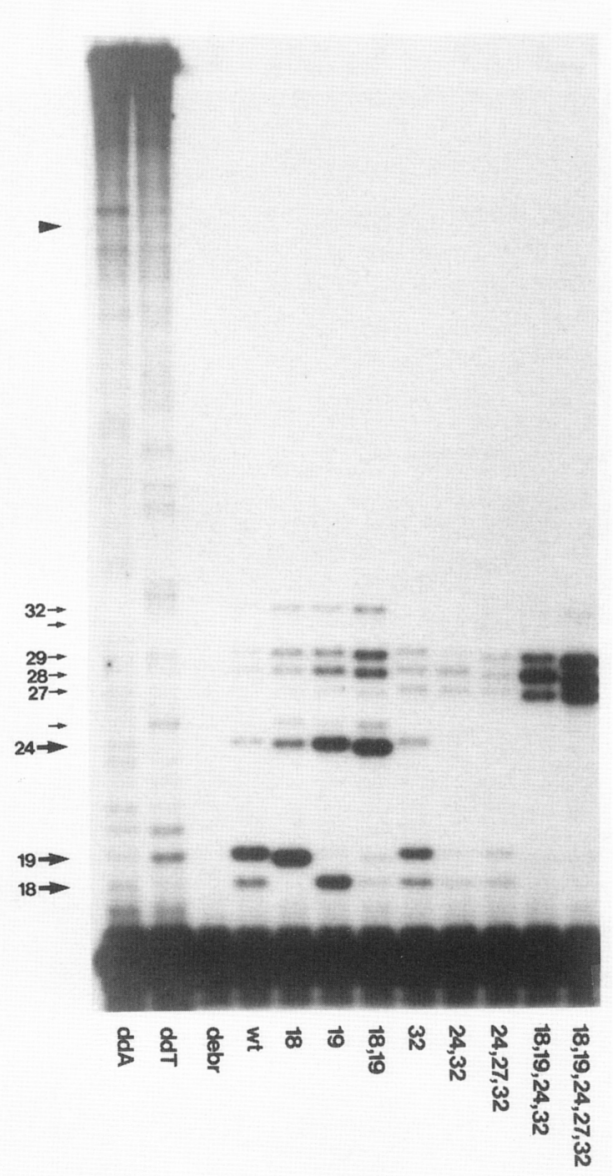

Figure 6. Branch site mutations influence the pattern of branch sites used in small-t and the cryptic splice. Small-t and cryptic lariat introns from the wild type and each of the mutants were purified as described in Fig. 1A. Branch sites were mapped for the lariat small-t $(A)$ and cryptic $(B)$ introns by primer extension, using the intron primer described in Fig. 1A. In each case, the branch sites used for the wild type are indicated by arrows. (debr) Primer extension of wild-type small-t and cryptic introns pretreated with debranching activity. Arrowheads indicate the positions of extension products elongated to the 5 ' ends of the debranched introns, which were more apparent on a longer exposure of the autoradiogram.

found to correspond to positions immediately upstream of the $5^{\prime}$ splice sites of large- $T$ and small-t and the $T / t$ branch site regions. Further evidence that these products reflect interactions relevant to pre-mRNA splicing includes the following (Noble et al. 1986; J. Noble, unpubl.): Protection products were detected only under conditions that allow pre-mRNA splicing le.g., ATP, $\mathrm{Mg}^{2+}$, and incubation at $30^{\circ} \mathrm{Cl}$, products were not formed with pre-RNAs transcribed from SV40 cDNA templates, and micrococcal nuclease pretreatment of nuclear extracts prevented splicing and protection product formation; but both were restored by addition of S100 extract.

We first used this protection assay to probe the effects of branch site mutations on factor binding to the $T / t$ branch site region. To determine the effects of muta- tions on branch site interactions, full-length wild-type and mutant precursors were processed in vitro, and branch site protection products were purified and analyzed by primer extension using the primer complementary to the $3^{\prime}$ exon. Although protection products were detected in greater amounts when uncapped precursors were used, they could also be detected with capped preRNAs (see Fig. 3), which therefore were used in these experiments. Several points are apparent from this analysis, which is shown in Figure 7. First, branch site protection gives rise to multiple species, comprising essentially four domains (Fig. 7, b1-b4). Second, the factor interactions represented by branch site protection were profoundly influenced by branch acceptor mutations. Although the effects of mutation were rather complex in some instances, each acceptor substitution affected 


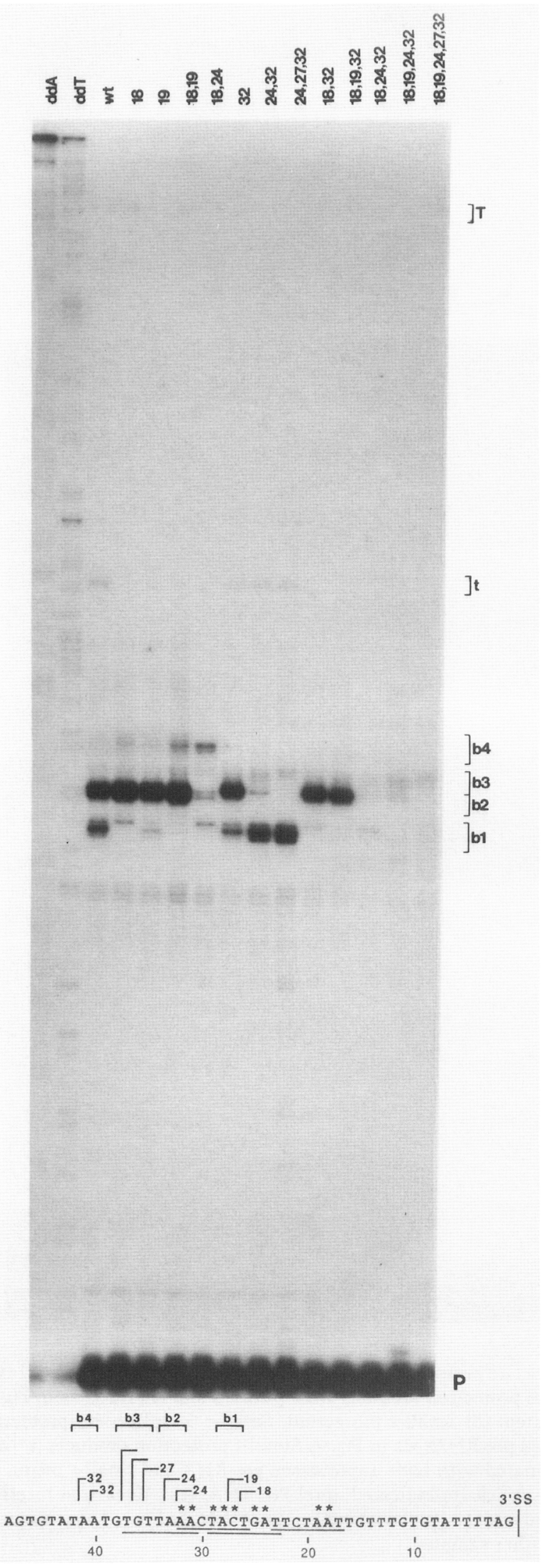

only one or two of the collection of branch site protection products in general. This correspondence between acceptor nucleotides and the $5^{\prime}$ ends of protection products, which is summarized at the bottom of Figure 7 , involved, in each case, the elimination of protection products whose $5^{\prime}$ ends mapped to positions 8 or $9 \mathrm{nu}-$ cleotides upstream of the branch nucleotide mutated. For the heavily substituted mutants, in which all of the major $\mathrm{T} / \mathrm{t}$ branch acceptors are mutated (i.e., $18,19,24,27,32$ ), branch site protection was essentially eliminated, with the exception of a minor set of products mapping to the $5^{\prime}$ limit of b3. Finally, the results suggest a competition between factors for different branch sites. Mutation of upstream branch sites resulted in increased factor binding to downstream sites, and, more dramatically, mutation of upstream sites led to greater interaction with downstream sites.

\section{Factor interactions with the large- $T$ and small- $T$ 5'} splice sites are affected differently by branch acceptor mutations

In view of the observed differences in sensitivity of large- $T$ and small-t splicing to branch site mutations, next we decided to analyze the effects of these mutations on factor binding to the large- $T$ and small-t $5^{\prime}$ splice sites. In each case, the $5^{\prime}$ ends of the resulting protection products mapped $\sim 10$ nucleotides upstream of the corresponding 5 ' splice site. For the analysis of large$T$ protection products, a full-length pre-RNA was used. Figure $8 \mathrm{~A}$ reveals that protection of the large- $\mathrm{T} 5^{\prime}$ splice site was largely unaffected by mutation of the $T / t$ branch acceptors. This lack of effect is apparent even in the case of the more heavily substituted mutants, most notably $18,19,24,27,32$, for which branch site protection was all but eliminated (see Fig. 7).

For analysis of small-t $5^{\prime}$ splice-site protection products, the wild-type and mutant pre-RNAs deleted for the large-T 5' splice site were used. The purified protection products were contaminated with the small- $t$ intron- $3^{\prime}$ exon intermediate, as well as unprocessed preRNA, and all of these species were detected by the exon primer used. The splicing intermediates were differen-

Figure 7. Branch site mutations influence factor interactions with the branch site region. Full-length wild-type and mutant pre-RNAs were incubated under splicing conditions in vitro, and species corresponding in size to branch site protection products purified and analyzed by primer extension using a primer complementary to $3^{\prime}$ exon (see Materials and methods). Protection products are grouped into four domains, designated bl-b4. Contaminating spliced large-T RNA and small-t $5^{\prime}$ splice-site protection species are also indicated. (P) Unextended primer. (Bottom) A schematic illustration of the $\mathrm{T} / \mathrm{t}$ branch site region. The correspondence between branch site mutations and elimination of protection products is indicated, as is the relationship between designations $\mathrm{bl}-\mathrm{b} 4$ and the branch acceptors required for generation of each protection products. Branch sites are indicated by stars. Sequences with homology to the mammalian branch site consensus are underlined. Numbers indicate distance in nucleotides upstream of the $3^{\prime}$ splice site. 

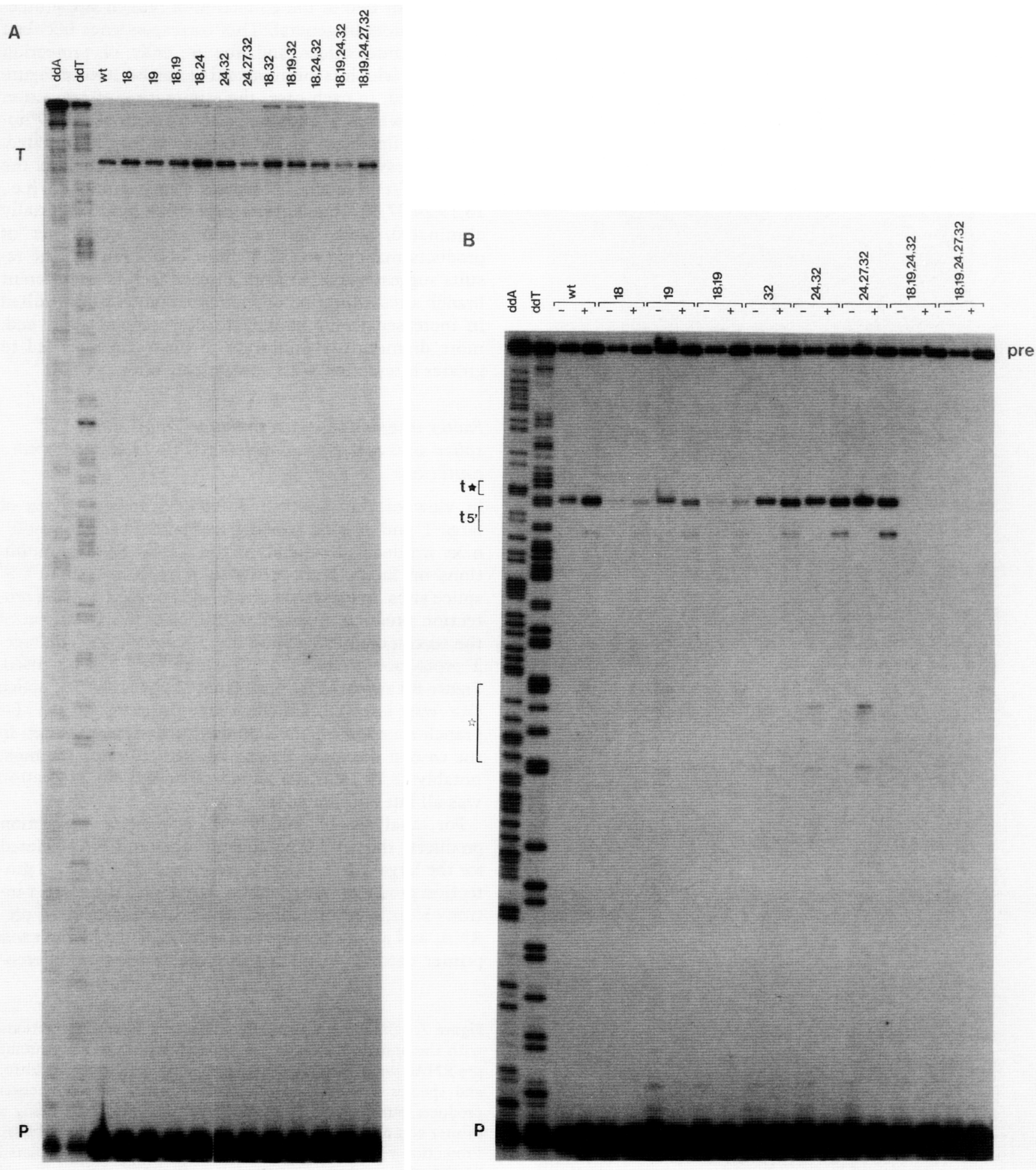

Figure 8. Branch site mutations prevent small-t but not large-T $5^{\prime}$ splice site protection. $(A)$ Large-T protection. Full-length wild-type and mutant pre-RNAs were processed in vitro, and large-T $5^{\prime}$ splice-site protection products were purified and analyzed as in Fig. 7. Large-T protection products $(T)$ and unextended primer $(\mathrm{P})$ are indicated. $(B)$ Small-t protection. Small-t $5^{\prime}$ splice-site protection products were purified from processing reactions containing $5^{\prime}$-truncated pre-RNAs, as in Fig. 7 . Small-t protection products $\left(t^{\star}\right)$ and unextended primer $(\mathrm{P})$ are indicated. Protection products were contaminated with both unprocessed pre-RNA and small-t intron-3' exon intermediate. Primer extension products corresponding to these species are indicated: (pre) Pre-RNA; $\left(t 5^{\prime}\right)$ linearized intermediate; (open star and bracket) lariat intermediates. Samples were analyzed with $(+)$ and without $(-\mid$ prior debranching. Twice as much of the debranched wild-type sample was applied to the gel, relative to other samples. 
tiated from protection products by their altered mobility following debranching. The results of the analysis of protection products, shown in Figure 8B, can be summarized in essentially three points. First, substitutions involving exclusively the most downstream branch acceptors, which are used in small-t splicing, significantly reduced the extent of protection of the small-t $5^{\prime}$ splice site. This effect was most severe for mutants containing a substitution of the acceptor at position 18 and correlates with the observed inhibition of small-t splicing in vivo and in vitro (Figs. 2 and 5). Second, mutations involving exclusively the more upstream branch acceptors (particularly 24,32 and $24,27,32$ ), which are used in vitro by cryptic and large-T splices, but not the small-t splice (see Figs. 4 and 6B), increased the level of small-t 5' splice-site protection. These mutations also enhanced the relative efficiency of small-t splicing in vivo and in vitro. Finally, mutation of upstream and downstream branch acceptors together completely eliminated protection of the small-t 5 ' splice site, as well as the formation of small-t splicing products and intermediates.

\section{Discussion}

Mutations of the major $T / t$ branch acceptors affect alternative splicing and branch site selection but not large- $T$ splicing in vitro

The analysis of branch acceptor mutations presented here suggests that branch nucleotide-dependent interactions can determine the alternative splicing pathways of SV40 early pre-mRNA. The data suggest that these effects are manifested as a competition between large- $T$ and small-t splicing for available branch sites. Thus, under conditions where competition does not occur, i.e., large-T splicing in vitro from full-length precursor or when small-t splicing is eliminated by mutation of its required downstream branch acceptors, multiple base substitutions in upstream branch acceptors, although altering branch site selection, do not significantly affect splicing. This insensitivity to branch site mutations is reminiscent of the lack of effect of similar mutations on splicing of the rabbit $\beta$-globin large intron (Hornig et al. 1986). However, under conditions that allow small-t splicing, mutations of upstream branch sites reduce the relative efficiencies of large- $T$ splicing in vivo and a cryptic splice in vitro. As discussed in more detail below, we believe this reflects a competition between splicing factors during spliceosome assembly.

An explanation for the lack of effect of large-T splicing of the heavily substituted branch acceptor mutations may come from analysis of branch site mutations in yeast. The conserved UACUAAC box appears to comprise two distinct elements: the branch site contextual consensus (UACUA_C) and the branch acceptor itself. These elements have been distinguished on the basis of suppressor mutations: Substitutions in the contextual consensus are rescued by complementary mutations in snR20 (Parker et al. 1987), whereas substitutions of the branch adenosine, which correspond to a bulge in the
snR20 : branch site complementarity, are suppressed by mutations in another factor (Couto et al. 1987). Mutation specifically of the branch acceptor has been shown to allow the assembly in yeast of prespliceosomal complexes containing the yeast analog of U2 snRNP (Pikielny et al. 1986). A role for the mammalian branch site contextual sequence in determining splicing efficiency, but not in spliceosome assembly, has also been reported recently (Reed and Maniatis 1988). By analogy, we believe that the multiple copies of the mutated branch site consensus used in large- $T$ splicing remain able to recruit factors for assembly of prespliceosomal complexes. We suggest that these complexes, which appear to be less stable, as measured by the RNase protection assay, are nonetheless able to use the best available branch sites for large- $\mathrm{T}$ or the cryptic splice, namely those at positions $27-29$.

The preference of the more heavily substituted $\mathrm{mu}-$ tants for use of branch acceptors at positions 27-29 for large-T splicing in vitro was somewhat surprising. These branch sites are unusual in the sense that the match to the consensus is poorer than the others $(4 / 6)$ and places a $\mathrm{C}$, and not the highly preferred $\mathrm{A}$, at the 'branch position' (Fig. 1D). However, $\mathrm{C}$ has been shown to function relatively efficiently as a branch acceptor in vitro (Hornig et al. 1986; Hartmuth and Barta 1988), and the earliest description of branches in nuclear RNA suggested that $\mathrm{C}$ might be used as an acceptor in vivo (Wallace and Edmonds 1983). An important constraint on branch site selection in higher eukaryotes appears to be the distance from the branch site to the $3^{\prime}$ splice junction, which is almost invariably between 18 and $37 \mathrm{nu}-$ cleotides (Reed and Maniatis 1985). Comparison of branch site sequences (reviewed in Green 1986) indicates that, given this constraint, the selection of a particular nucleotide as the branch acceptor is governed principally by the identity of the nucleotide (A preferred) and the homology of the branch site context to the consensus. Our data suggest that once this preference has been eliminated, the choice of branch sites is determined primarily by distance from the 3 ' splice junction, which, for positions 27 and 28 , is precisely midway between the effective spatial limits observed for introns generally in higher eukaryotes.

Small-t splicing is completely inhibited by downstream branch site mutations

In contrast to large-T splicing in vivo and the cryptic splice in vitro, splicing to small-t mRNA depends critically on the identity of the downstream branch nucleotides. We believe that the strict requirement for $\mathrm{A}$ at branch acceptor positions 18 and 19 in small-t splicing, as compared with large- $T$ splicing, derives from at least two factors. First, small-t splicing is constrained to use one of these two branch acceptors. By analyzing branch sites used in an expanded intron, we have shown that this constraint is due to the need for a minimum separation between the small-t $5^{\prime}$ splice site and branch site (J. Noble, unpubl.). This steric constraint not only ap- 
pears to influence the selection of branch sites but also, and perhaps more significantly, the pathway involved in the assembly of the small-t spliceosome (see below). Second, splicing of the early pre-mRNA to small $t$ in vivo and in vitro involves a competition between alternative splicing pathways. By analogy to the effects of upstream mutations on large-T splicing, we believe that this competition accentuates the effect of branch acceptor substitutions on the efficiency of small-t splicing.

Factor interactions with the $T / t$ branch site region are influenced by the identity of the branch nucleotide

The analysis of branch site protection products has indicated that factor interactions with the branch site region are extremely sensitive to the identity of the branch nucleotide. Bearing in mind the possible existence of a base-pairing interaction between U2 snRNA and the branch site consensus, we believe that the most likely explanation for this effect is that the bulge generated by U2 snRNA : branch site duplex is recognized by some, as yet unknown, factor. The identification in yeast of a locus distinct from that for snR20 that can suppress a branch acceptor mutation (Couto et al. 1987) suggests the existence of a factor that recognizes the branch nucleotide. We suggest that a factor, possibly a component of $\mathrm{U} 2$ or U1 snRNPs, is also required for recognition of the branch nucleotide in higher eukaryotes and that binding of this factor, which is prevented by the substitution of $\mathrm{U}$ for an $\mathrm{A}$ at this position, contributes to the stability of factor interactions with the branch site.

\section{Alternative splicing of SV40 early pre-RNA is determined by a competition for branch sites and by factor interactions during the early stages of spliceosome assembly}

Previous work by others has indicated the existence of two distinct phases of interaction of U1 snRNP with the $5^{\prime}$ splice site (Ruskin and Green 1985b; Bindereif and Green 1987; Chabot and Steitz 1987). The initial interaction, which protects primarily the $5^{\prime}$ splice site consensus, does not require $3^{\prime}$ splice site and branch site sequences or intact U2 snRNP. The second phase, which appears more stable, and protects sequences extending both $5^{\prime}$ and $3^{\prime}$ of the consensus, depends critically on U2 snRNP and $3^{\prime}$ splice site sequences. This latter phase presumably reflects an interaction of $U 1$ and $U 2$ snRNPs that occurs at an early stage of spliceosome assembly. The facts that factor interactions at the large- $T$ and small-t $5^{\prime}$ splice sites are detected very early in the splicing reaction and depend on intact $\mathrm{U} 2$, as well as $\mathrm{U} 1$, snRNPs (J.C.S. Noble, H. Ge, M. Chaudhuri, and J. Manley, in prep.) suggest that they both correspond to the second phase of interaction with $5^{\prime}$ splice sites. However, protection of the small-t $5^{\prime}$ splice site lags, compared to that of the large-T $5^{\prime}$ splice site, and occurs simultaneously with protection of the branch site region (J.C.S. Noble, H. Ge, M. Chaudhuri, and J. Manley, in prep.). These differences between the timing and re- quirements of $5^{\prime}$ splice site protection for the two splices, coupled with the observations presented here that small-t, but not large- $\mathrm{T}$, protection is eliminated by mutation of the major branch acceptors, provide an explanation for the different sensitivities of large- $T$ and small-t splicing to branch acceptor mutations. We suggest that relatively unstable factor binding to the small-t splice site/branch site region during the early stages of small-t spliceosome assembly renders complex formation dependent upon the added stabilization afforded by recognition of the branch nucleotide. The most likely source of this instability is the proximity of the small- $t$ $5^{\prime}$ splice site and branch site regions, which results in steric hindrance between factor binding to these two regions of the pre-RNA. The effect of this added requirement for branch acceptor recognition for small-t spliceosome assembly would be accentuated by the competition between this pathway and alternative assembly pathways (large-T in vivo and the cryptic splice in vitro), which would not be subject to these steric effects.

The existence of such a competition has relevance to the correlation observed previously between cell-specific influences on $\mathrm{T} / \mathrm{t}$ mRNA ratios in vivo (Fradin et al. 1984; Fu and Manley 1987) and the pattern of branch sites used in large-T splicing (Noble et al. 1987). The predominant branch sites used in large-T splicing in human 293 cell nuclear extracts and in Xenopus laevis oocytes were found to be shifted upstream, compared to those used in HeLa nuclear extracts, resulting in a reduced overlap between small-t and large-T branch site patterns (Noble et al. 1987). This reduced overlap, when interpreted in light of the competition between splicing pathways for branch sites described here, provides an explanation for the enhanced relative efficiency of small-t splicing in vivo in these cell types.

Although the multiple branch site pattern observed for large-T splicing may not be a universal feature of alternative splicing involving multiple $5^{\prime}$ splice sites joined to a single $3^{\prime}$ splice site [splicing of the adenovirus E1A pre-mRNA appears to involve only a single site for all three alternative splicing pathways (Schmitt et al. 1987)], we believe that a similar competition between alternative spliceosome assembly pathways for factors bound to a branch site may determine the alternative splicing pattern even in cases in which a single branch site is involved. Although it is unclear how frequently other pre-mRNAs will use branch site interactions to control alternative splicing, we suggest that competition between trans-acting factors for sites on a pre-RNA that result in commitment to a specific splicing pathway may be a general strategy for regulating alternative splicing.

\section{Materials and methods}

\section{plasmid construction}

The template for oligonucleotide-directed mutagenesis was constructed by cloning an 1169-nucleotide HindIII fragment derived from the early region of SV40 (nucleotides 5171-4002) into M13mp18. Mutagenesis was performed using a 50-mer 'mixed' oligonucleotide (5'-ATGTGTTAAACTACTGATTCT 
AATTGTTTGTGTATTTTAGATTCCAACCT-3') corresponding to nucleotides 4611-4561, which was synthesized with an equal mixture of $\mathrm{A}$ and $\mathrm{T}$ at the four positions underlined. The method employed was essentially as described by Kunkel et al. (1987). Screening for potential mutants involved DNA sequencing (Sanger et al. 1977), using a primer (5'-GGA CAAACTACCTACAG-3') located $\sim 70$ nucleotides upstream of the region mutagenized. To create the $\mathrm{C} \rightarrow \mathrm{T}$ change at position -27 , an 18-mer (5'-TGTTATACTATTGTTTCT-3'), corresponding to nucleotides $4608-4590$, was used with DNA previously mutated at $18,19,24$, and 32 as template.

For in vivo analysis, point mutations were transferred into the vector pSTER by ligating BstXI-PfIMI fragments (SV40 nucleotides 4759-4558), together with PfIMI-BamHI (SV40 nucleotides 4558-2533) and BamHI-BstXI (pBR322 nucleotide 375 to SV40 nucleotide 4759 ) fragments derived from wild-type pSTER (Fu and Manley 1987). For in vitro analysis, HindIII fragments containing the same point mutations were subcloned into the HindIII site of pGEM3. In the case of the $5^{\prime}$ end-truncated constructs, NlaIV-HindIII fragments (nucleotides 4696-4002) derived from wild-type and selected mutants, were subcloned into the vector pGEM4, which had been digested previously with EcoRI, flush ended with Klenow fragment, and digested with HindIII.

\section{Transfection and S1 analysis}

HeLa cells were tranfected with $25 \mu \mathrm{g}$ plasmid DNA per 150 mM plate, as described by Fu and Manley (1987). Transient expression was terminated $\sim 48 \mathrm{hr}$ after DNA addition, and RNA was isolated essentially as described by Fu and Manley (1987). Analysis of RNA was performed using a $3^{\prime}$ end-labeled HindIII-BsmI fragment probe (nucleotides 5171-4528) isolated from plasmid pSTER-i11, which contains an 11-nucleotide EcoRI linker inserted at nucleotide 4612, between the small-t $5^{\prime}$ splice site and branch site region. The use of this probe permitted an estimation of unspliced pre-mRNA in the analysis of nuclear RNA. S1 mapping using total cytoplasmic RNA was performed as decribed previously.

\section{In vitro splicing}

Capped precursor RNAs were produced by runoff transcription with SP6 RNA polymerase of templates linearized either at the SalI site (full-length pre-RNAs) or the HindIII site $\left(5^{\prime}\right.$ end-truncated pre-RNAs) in the vector polylinker, essentially as described by Krainer et al. (1984). Approximately 0.25 pmole RNA was incubated in 100- $\mu$ l reactions containing $40 \mu \mathrm{l} \mathrm{HeLa} \mathrm{cell}$ nuclear extract (Dignam et al. 1983), under conditions described previously (Ruskin and Green 1985a; Noble et al. 1986). Reactions were terminated after $3 \mathrm{hr}$, and RNA extracted after proteinase-K digestion (Krainer et al. 1984) and analyzed on $5 \%$ denaturing polyacrylamide gels. Lariat introns, splicing intermediates, and protection products were purified from gels, using the method of Maxam and Gilbert (1980). Debranching of lariat RNAs was carried out as described previously (Ruskin and Green 1985a; Noble et al. 1987).

\section{Branch site mapping and protection product analysis}

Branch sites and the $5^{\prime}$ ends of protection products were mapped by primer extension. The primer used in the case of lariat introns was a 14-mer (5'-CTAAAATACACAAA-3') complementary to the last 14 nucleotides of the $\mathrm{T} / \mathrm{t}$ intron (nucleotides 4585-4521). The primer used for intermediates was a $32-$ mer $\quad 5^{\prime}$-CCTCATTAAAGGCATTCCACCACTGCTCCCAT- $3^{\prime}$ ), complementary to a region of the $3^{\prime}$ exon (nucleotides $4548-4516) \sim 55$ nucleotides downstream of the $\mathrm{T} / \mathrm{t} 3^{\prime}$ splice junction. For primer extension using the intron primer, 1-5 fmoles of purified intron and 5-10 fmoles of $5^{\prime}$ end-labeled primer was lyophilized and resuspended in $10 \mu \mathrm{l}$ of a hybridization buffer containing $10 \mathrm{~mm}$ Tris- $\mathrm{Cl}$ ( $\mathrm{pH} 8.0), 1 \mathrm{~mm}$ EDTA, and $250 \mathrm{mM} \mathrm{KCl}$. After denaturation at $70^{\circ} \mathrm{C}$ for $10 \mathrm{~min}$, hybridization was performed at $10-11^{\circ} \mathrm{C}$ for $20 \mathrm{hr}$. At the end of this period, $25 \mu \mathrm{l}$ of ice-cold buffer A containing $30 \mathrm{~mm}$ Tris- $\mathrm{Cl} / \mathrm{pH}$ 8.4 ), $20 \mathrm{mM} \mathrm{KCl}$, and $16 \mathrm{mM} \mathrm{MgCl}$ was added, followed by 5.5 $\mu l$ of a mixture of $1.8 \mathrm{~mm}$ each $\mathrm{dNTP}, 72 \mathrm{~mm}$ dithiothreitol (DTT), and $180 \mu \mathrm{g} / \mathrm{ml}$ actinomycin D. Primer extension was then initiated by the addition of 10 units of reverse transcriptase (Life Sciences) and continued for $2 \mathrm{hr}$ at $13-14^{\circ} \mathrm{C}$. Markers were generated with the same protocol, except that 250 fmoles of precursor RNA and 25 fmoles of primer were used. In this case, $12.5 \mu \mathrm{l}$ of buffer $\mathrm{A}$ and $15 \mu \mathrm{l}$ of an appropriate dideoxy mix (Promega-Biotec) were added. Primer extension was terminated by the addition of $80 \mu \mathrm{l}$ ice-cold $0.3 \mathrm{M}$ sodium acetate $(\mathrm{pH} 5.2)$ and ethanol precipitation. cDNA products were analyzed on $15 \%$ denaturing polyacrylamide gels.

For primer extension using the exon primer, 1-5 fmoles of purified intermediate or protection product and 5-10 fmoles of $5^{\prime}$ end-labeled primer were coprecipitated and resuspended in $15 \mu \mathrm{l}$ of a hybridization buffer containing $70 \%$ / $\mathrm{vol} /$ vol) formamide, $0.4 \mathrm{M} \mathrm{NaCl}, 40 \mathrm{mM}$ PIPES (pH 6.4), and $1 \mathrm{~mm}$ EDTA. After denaturation at $80^{\circ} \mathrm{C}$ for $10 \mathrm{~min}$, hybridization was performed at $30^{\circ} \mathrm{C}$ for $14 \mathrm{hr}$, and hybrids were recovered by precipitation with ethanol and resuspended in $25 \mu \mathrm{l}$ of a buffer containing $10 \mathrm{~mm}$ Tris- $\mathrm{Cl}(\mathrm{pH} 8.4), 100 \mathrm{~mm} \mathrm{NaCl}$, and $1 \mathrm{~mm}$ EDTA. Twenty-five microliters of a mixture containing 100 mM Tris-Cl (pH 8.4), $10 \mathrm{~mm}$ DTT, $16 \mathrm{mM} \mathrm{MgCl}_{2}, 40 \mu \mathrm{g} / \mathrm{ml}$ actinomycin $\mathrm{D}$, and $500 \mu \mathrm{M}$ of each dNTP was then added, and primer extension performed by adding 10 units of reverse transcriptase and incubating for $1 \mathrm{hr}$ at $40^{\circ} \mathrm{C}$. Markers were generated by an adaptation of this protocol similar to that described above. Primer extension was terminated by ethanol precipitation and products were analyzed on $6 \%$ denaturing polyacrylamide gels.

\section{Acknowledgments}

We thank X.-Y. Fu for helpful advice on transfection and S1 analysis. We are also grateful to E.K. Cheung for help in screening the point mutants and M. Kapczynski for assistance in cell culture. We thank $H$. Robertson and R. Krug for comments on the manuscript. This work was supported by $\mathrm{Na}$ tional Institutes of Health grants CA-33620 and CA-46121.

\section{References}

Bindereif, A. and M.R. Green. 1986. Ribonucleoprotein complex formation during pre-mRNA splicing in vitro. Mol. Cell. Biol. 6: 2582-2592.

1987. An ordered pathway of snRNP binding during mammalian pre-mRNA splicing complex assembly. $E M B O$ I. 6: 2415-2424.

Black, D.L., B. Chabot, and J.A. Steitz. 1985. U2 as well as U1 small nuclear ribonucleoproteins are involved in premessenger RNA splicing. Cell 42: 737-750.

Breitbart, R.E., A. Andreadis, and B. Nadal-Ginard. 1987. Alternative splicing: A ubiquitous mechanism for the generation of multiple protein isoforms from single genes. Annu. Rev. Biochem. 56: 467-495.

Brody, E. and J. Abelson. 1985. The 'spliceosome': Yeast pre- 
messenger RNA associates with a $40 \mathrm{~S}$ complex in a splicing-dependent reaction. Science 228: 963-967.

Chabot, B. and J.A. Steitz. 1987. Multiple interactions between the splicing substrate and small nuclear ribonucleoproteins in spliceosomes. Mol. Cell. Biol. 7: 281-293.

Chabot, B., D. Black, D.M. LeMaster, and J.A. Steitz. 1985. The $3^{\prime}$ splice site of pre-messenger RNA is recognized by a small nuclear ribonucleoprotein. Science 230: 1344-1349.

Couto, J.R., J. Tamm, R. Parker, and C. Guthrie. 1987. A transacting suppressor restores splicing of a yeast intron with a branch point mutation. Genes Dev. 1: 445-455.

Dignam, J.D., R.M. Lebovitz, and R.G. Roeder. 1983. Accurate transcription initiation by RNA polymerase II in a soluble extract from isolated nuclei. Nucleic Acids Res. 11: 14751489.

Domdey, H., B. Apostol, R.-J. Lin, A. Newman, E. Brody, and J. Abelson. 1984. Lariat structure are in vivo intermediates in yeast pre-mRNA splicing. Cell 39: 611-621.

Fouser, L.A. and J.D. Friesen. 1986. Mutations in a yeast intron demonstrate the importance of specific conserved nucleotides for the two stages of nuclear mRNA splicing. Cell 45: $81-93$.

Fradin, A., R. Jove, C. Hemenway, H.D. Keiser, J.L. Manley, and C. Prives. 1984. Splicing pathways of SV40 mRNAs in $X$. laevis oocytes differ in their requirements for snRNPs. Cell 37: 927-936.

Frendewey, D. and W. Keller. 1985. The stepwise assembly of a pre-mRNA splicing complex requires U-snRNPs and specific intron sequences. Cell 42: 355-367.

Freyer, G.A., J. Arenas, K.K. Perkins, H.M. Furneaux, L. Pick, B. Young, R.J. Roberts, and J. Hurwitz. 1987. In vitro formation of a lariat structure containing a G2'-5' G linkage. I. Biol. Chem. 262: 4267-4273.

Fu, X.-Y. and J.L. Manley. 1987. Factors influencing alternative splice site utilization in vivo. Mol. Cell. Biol. 7: 738-748.

Fu, X.-Y., J. Colgan, and J.L. Manley. 1988a. Multiple cis-acting sequence elements are required for efficient splicing of SV40 small t pre-mRNA. Mol. Cell. Biol. 8: 3582-3590.

Fu, X.-Y., H. Ge, and J.L. Manley. 1988b. The role of the polypyrimidine stretch at the SV40 early pre-mRNA 3 ' splice site in alternative splicing. EMBO /. 7: 809-817.

Gattoni, R., P. Schmitt, and J. Stevenin. 1988. In vitro splicing of adenovirus ElA transcripts: Characterization of novel reactions and of multiple branch points abnormally far from the 3' splice site. Nucleic Acids Res. 16: 2389-2409.

Gerke, V. and J.A. Steitz. 1986. A protein associated with small nuclear ribonucleoprotein particles recognizes the 3 ' splice site of pre-messenger RNA. Cell 47: 973-984.

Grabowski, P.J. and P.A. Sharp. 1986. Affinity chromatography of splicing complexes: U2, U5 and U4 + U6 small nuclear ribonucleoprotein particles in the spliceosome. Science 223: $1294-1299$.

Grabowski, P., R.A. Padgett, and P.A. Sharp. 1984. Messenger RNA splicing in vitro: An excised intervening sequence and a potential intermediate. Cell 37: 415-427.

Grabowski, P., S.R. Seiler, and P.A. Sharp. 1985. A multicomponent complex is involved in the splicing of messenger RNA precursors. Cell 42: 345-353.

Green, M.R. 1986. Pre-mRNA splicing. Annu. Rev. Genet. 20: $671-708$

Hartmuth, K. and A. Barta. 1988. Unusual branch point selection in processing of human growth hormone pre-mRNA. Mol. Cell. Biol. 8: 2011-2020.

Hornig, H., M. Aebi, and C. Weissmann. 1986. Effect of mutations at the lariat branch acceptor site on $\beta$-globin premRNA splicing in vitro. Nature 324: 589-591.
Jacquier, A., J.R. Rodriguez, and M. Rosbash. 1985. A quantitative analysis of the effects of $5^{\prime}$ junction and TACTAAC box mutants and mutant combinations on yeast mRNA splicing. Cell 43: 423-430.

Keller, E.B. and W.A. Noon. 1984. Intron splicing: A conserved internal signal in introns of animal pre-mRNAs. Proc. Natl. Acad. Sci. 81: 7417-7420.

Konarska, M.M. and P.A. Sharp. 1987. Interactions between small nuclear ribonucleoprotein particles in the formation of spliceosomes. Cell 49: 763-774.

Krainer, A.R. and T. Maniatis. 1985. Multiple factors including the small nuclear ribonucleoproteins $U 1$ and $U 2$ are necessary for pre-mRNA splicing in vitro. Cell 42: 725-736.

Krainer, A.R., T. Maniatis, B. Ruskin, and M.R. Green. 1984. Normal and mutant human $\beta$-globin pre-mRNAs are faithfully and efficiently spliced in vitro. Cell 36: 993-1005.

Kunkel, T.A., I.D. Roberts, and R.A. Zakour. 1987. Rapid and efficient site-specific mutagenesis without phenotypic selection. Methods Enzymol. 154: 367-382.

Langford, C.J. and D. Gallwitz. 1983. Evidence for an introncontained sequence required for the splicing of yeast RNA polymerase II transcripts. Cell 33: 519-527.

Langford, C.J., F.-J. Klinz, C. Donath, and D. Gallwitz. 1984. Point mutations identify the conserved intron-contained TACTAAC box as an essential splicing sequence in yeast. Cell 36: 645-653.

Lin, R.-J., A.J. Newman, S.-C. Cheng, and J. Abelson. 1985. Yeast mRNA splicing in vitro. J. Biol. Chem. 260: 1478014792.

Manley, J.L., J.C.S. Noble, X.-Y. Fu, and H. Ge. 1987. Factors that influence alternative splice site selection in vitro. In Molecular biology of RNA: New perspectives (ed. M. Inouye and B.S. Dudock), pp. 97-112. Academic Press, New York.

Maxam, A. and W. Gilbert. 1980. Sequencing end-labeled DNA with base-specific chemical cleavages. Methods Enzymol. 65: 499-560.

Mount, S.M., I. Petterson, M. Hinterberger, A. Karmas, and J.A. Steitz. 1983. The Ul small nuclear RNA-protein complex selectively binds a 5 ' splice site in vitro. Cell 33: 509-518.

Newman, A.J., R.-J. Lin, S.-C. Cheng, and J. Abelson. 1985. Molecular consequences of specific intron mutations on yeast mRNA splicing in vivo and in vitro. Cell 42: 335-344.

Noble, J.C.S., C. Prives, and J.L. Manley. 1986. In vitro splicing of simian virus 40 early pre-mRNA. Nucleic Acids Res. 14: $1219-1235$.

Noble, J.C.S., Z.-Q. Pan, C. Prives, and J.L. Manley. 1987. Splicing of SV40 early pre-mRNA to large $T$ and small $t$ mRNAs utilizes different patterns of lariat branch sites. Cell 50: $227-236$.

Padgett, R., P.J. Grabowski, M.M. Konarska, S.R. Seiler, and P.A. Sharp. 1986. Splicing of messenger RNA precursors. Annu. Rev. Biochem. 55: 1119-1150.

Padgett, R., M.M. Konarska, P.J. Grabowski, S.F. Hardy, and P.A. Sharp. 1094. Lariat RNA's as intermediates and products in the splicing of messenger RNA precursors. Science 225: 898-903.

Padgett, R.A., M.M. Konarska, M. Aebi, H. Hornig, C. Weissmann, and P.A. Sharp. 1985. Nonconsensus branch-site sequences in the in vitro splicing of transcripts of mutant rabbit $\beta$-globin genes. Proc. Natl. Acad. Sci. 82: 8349-8353.

Parker, R., P.G. Siliciano, and C. Guthrie. 1987. Recognition of the TACTAAC box during mRNA splicing in yeast involves base pairing of the U2-like snRNA. Cell 49: 229-239.

Pikielny, C.W., B.C. Rymond, and M. Rosbash. 1986. Electrophoresis of ribonucleoproteins reveals an ordered assembly pathway of yeast splicing complexes. Nature 324: 341-345. 
Pikielny, C.W., J.L. Teem, and M. Rosbash. 1983. Evidence for the biochemical role of an internal sequence in yeast nuclear mRNA introns: Implications for U1 RNA and metazoan mRNA splicing. Cell 34: 395-403.

Reed, R. and T. Maniatis. 1985. Intron sequences involved in lariat formation during pre-mRNA splicing. Cell 41: 95105.

- 1988. The role of the mammalian branch point sequence in pre-mRNA splicing. Genes Dev. 2: 1268-1276.

Rodriguez, J.R., C.W. Pikielny, and M. Rosbash. 1984. In vivo characterization of yeast mRNA processing intermediates. Cell 39: 603-610.

Ruskin, B. and M.R. Green. 1985a. An RNA processing activity that debranches RNA lariats. Science 229: 135-140.

. 1985b. Specific and stable intron-factor interactions are established early during in vitro pre-mRNA splicing. Cell 43: $131-142$.

Ruskin, B., J.M. Green, and M.R. Green. 1985. Cryptic branch point activation allows accurate in vitro splicing of human $\beta$-globin intron mutants. Cell 41: 833-834.

Ruskin, B., P.D. Zamore, and M.R. Green. 1988. A factor, $\mathrm{U} 2 \mathrm{AF}$, is required for $\mathrm{U} 2$ snRNP binding and complex assembly. Cell 52: 207-219.

Ruskin, B., A.R. Krainer, T. Maniatis, and M.A. Green. 1984. Excision of an intact intron as a novel lariat structure during pre-mRNA splicing in vitro. Cell 38: 317-331.

Sanger, F., S. Nicklen, and A.R. Coulson. 1977. DNA sequencing with chain-terminating inhibitors. Proc. Natl. Acad. Sci. 74: 5463-5467.

Schmitt, P., R. Gattoni, P. Keohavong, and J. Stevinin. 1987. Alternative splicing of ElA transcripts of adenovirus requires appropriate ionic conditions in vitro. Cell 50: $31-39$.

Shelness, G.S., R. Binder, S.-P.L. Hwang, C. MacDonald, D.A. Gordon, and D.L. Williams. 1987. Sequence and structural elements associated with the degradation of apolipoprotein II messenger RNA. In Molecular biology of RNA: New perspectives (ed. M. Inouye and B.S. Dudock), pp. 381-399. Academic Press, New York.

Tazi, I., C. Alibert, J. Temsamani, I. Reveillaud, G. Cathala, C. Burnel, and P. Jeanteur. 1986. A protein that specifically recognizes the 3' splice site of mammalian pre-mRNA introns is associated with a small nuclear ribonucleoprotein. Cell 47: 755-766.

van Santen, V.L. and R.A. Spritz. 1986. Alternative splicing of SV40 early pre-mRNA in vitro. Nucleic Acids Res. 14: $9911-9926$.

Vijayraghavan, V., R. Parker, J. Tamm, Y. Iimura, J. Rossi, J. Abelson, and C. Guthrie. 1986. Mutations in conserved intron sequences affect multiple steps in the yeast splicing pathway, particularly assembly of the spliceosome. $E M B O J$. 5: 1683-1695.

Wallace, J.C. and M. Edmonds. 1983. Polyadenylated nuclear RNA contains branches. Proc. Natl. Acad. Sci. 80: 950-954.

Zeitlin, S. and A. Efstratiadis. 1984. In vivo splicing products of the rabbit $\beta$-globin pre-mRNA. Cell 39: 589-602.

Zhuang, Y. and A.M. Weiner. 1986. A compensatory base change in Ul snRNA suppresses a $5^{\prime}$ splice site mutation. Cell 46: 827-835.

Zhuang, Y., H. Leung, and A.M. Weiner. 1987. The nature $5^{\prime}$ splice site of simian virus 40 large $T$ antigen can be improved by increasing the base complementary to U1 RNA. Mol. Cell. Biol. 7: 3018-3020. 


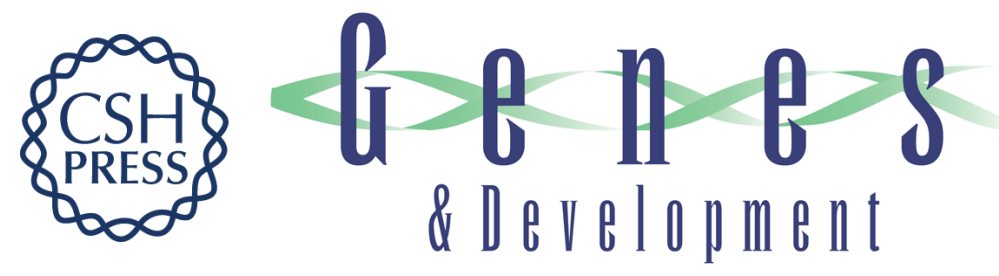

\section{Alternative splicing of SV40 early pre-mRNA is determined by branch site selection.}

J C Noble, C Prives and J L Manley

Genes Dev. 1988, 2:

Access the most recent version at doi:10.1101/gad.2.11.1460

References This article cites 62 articles, 17 of which can be accessed free at:

http://genesdev.cshlp.org/content/2/11/1460.full.html\#ref-list-1

License

Email Alerting

Service

Receive free email alerts when new articles cite this article - sign up in the box at the top right corner of the article or click here.

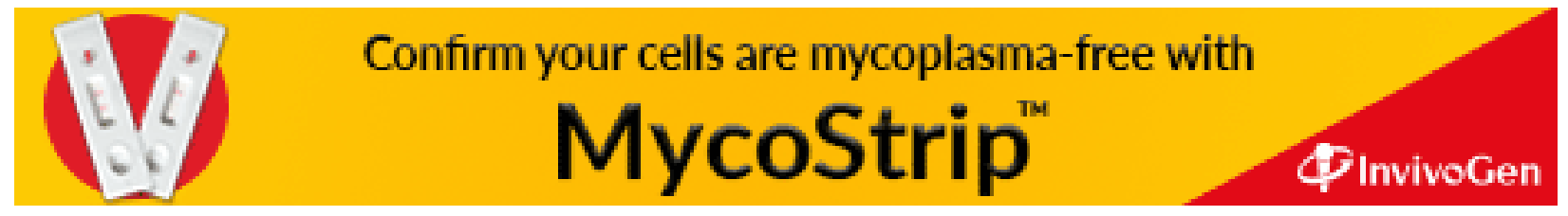

